\title{
Bioseguridad en Procedimientos Quirúrgicos
}

\author{
David Andrés Velásquez Argueta \\ Ingrid Manuela Baquiax Yax \\ Maritza Elodia Marina Eulalia Cupil Barrios \\ Ricardo Antonio Ovalle Rubio \\ Shamma Díaz Barillas \\ Víctor Manuel Yacón Pichol \\ Jose Manuel Arriaga
}

La Organización Mundial de la Salud definió al COVID-19 como una enfermedad infecciosa causada por un coronavirus de reciente descubrimiento denominado covid-sars. Tanto el nuevo virus como la enfermedad eran desconocidos antes de que estallara el brote en Wuhan (China) en diciembre de 2019. Esta enfermedad se caracteriza por una alta virulencia, lo que causó su rápida extensión a varios países del mundo a un ritmo acelerado y fue declarada pandemia el 11 de marzo de 2020.

Dos días después de declararse la pandemia, se presentó el primer caso en Guatemala. Los datos oficiales indicaban que para el 2 de abril había 46 casos positivos, de los cuales 45 pacientes estaban vivos y 1 fallecido.

En el momento actual hay varios estudios sobre la atención a estos pacientes desde el punto de vista clínico, médico y de cuidado crítico. Sin embargo, la literatura desde el punto de vista quirúrgico es más limitada. El cirujano debe atender a todo paciente potencialmente quirúrgico. Esta atención debería realizarse por equipo preparado para la atención de un paciente con COVID-19, pero la magnitud del brote actual dificulta tomar las medidas de precaución necesarias y la derivación a centros de referencia. En algunos centros se propuso inicialmente el tratamiento quirúrgico únicamente a procedimientos de emergencia y procedimientos electivos no demorables. Posteriormente, las medidas de contención incluyeron el cierre de servicios de consulta externa, lo que disminuyó el número de procedimientos, más no la cancelación de la totalidad de las cirugías programadas.

Tabla 1. Procedimientos quirúrgicos realizados en el Hospital Regional de Occidente del 13 de marzo a 05 de abril de 2020.

\begin{tabular}{|c|c|c|c|}
\hline PROCEDIMIENTOS DE EMERGENCIA & TOTAL & PROCEDIMIENTOS ELECTIVOS & TOTAL \\
\hline Apendicectomía & 44 & Colecistectomía videolaparoscópica & 11 \\
\hline Drenaje de hematoma cerebral & 14 & Traqueostomía abierta & 5 \\
\hline LPE & 12 & Lavado y desbridamiento & 4 \\
\hline Lavado y desbridamiento & 10 & Herniotomía inguinal & 3 \\
\hline
\end{tabular}




\begin{tabular}{|c|c|c|c|}
\hline Colocación de VDVP & 9 & Gastrostomía abierta & 3 \\
\hline Traqueotomía & 7 & Biopsia excisional & 3 \\
\hline Gastrostomías & 3 & Exploración de vías biliares & 2 \\
\hline Drenaje de absceso & 6 & $\begin{array}{c}\text { Colangiopancreatografía Retrógrada } \\
\text { Endoscópica }\end{array}$ & 2 \\
\hline Colecistectomía & 6 & Amigdalectomía & 1 \\
\hline Amputación infracondílea & 3 & Cierre de lleostomía & 1 \\
\hline Hernia incarcerada & 3 & Drenaje de absceso en glúteo & 1 \\
\hline Ventriculostomía & 3 & $\begin{array}{c}\text { Drenaje de hematoma en pared abdomi- } \\
\text { nal }\end{array}$ & 1 \\
\hline ERCP & 1 & Gastrostomía percutánea & 1 \\
\hline Rotación de colgajo & 1 & Cierre de gastrosquisis & 1 \\
\hline Levantamiento óseo & 2 & & \\
\hline Mielomeningoplastia & 1 & & \\
\hline LyD + colocación de VAC & 1 & & \\
\hline Hidrocelectomia & 1 & & \\
\hline Drenaje de hematoma en escroto & 1 & & \\
\hline TOTAL & 128 & TOTAL & 39 \\
\hline
\end{tabular}

La tabla 1 detalla el número de procedimientos realizados durante la parte de la fase de contención de la pandemia. Esta situación cobra relevancia principalmente porque se desconoce el estado serológico del paciente y el contacto estrecho podría causar una infección al personal de servicios quirúrgicos. Con esta consideración, es importante desde el primer acercamiento conocer el historial de exposición del paciente atendido en los diferentes servicios de cirugía y con mayor énfasis en los servicios de emergencia para determinar si el paciente pudo haber estado expuesto al virus, y si este fuera el caso, optar por tratamientos médicos o conservadores en la medida que esto sea apropiado para el cuadro clínico.

Se debe tener en cuenta que la cirugía urgente en pacientes confirmados con COVID 19 se considera como contraindicación especialmente en pacientes 
inmunocomprometidos, oncológicos o con patología respiratoria.

Entre las medidas a tomar en cuenta en la atención de pacientes quirúrgicos se consideran las siguientes:

1. Uso de bata de preferencia impermeable.

2. Mascarilla: idealmente se utilizará mascarilla N95 o FFP2/FF3 sin válvulas y no se recomienda la mascarilla convencional ya que no protege contra aerosoles.

3. Gafas: es fundamental la cobertura ocular de pantalla completa.

4. Pantalla de cobertura Facial: especialmente importante en el manejo de la vía aérea, en caso de utilizar gafas graduadas debe colocarse ajustarse sobre los mismos.

5. Guantes de nitrilo largos: es suficiente un par.

6. Es recomendable recogerse el cabello en mujeres y el afeitado de barba en varones para obtener la adecuada fijación de la mascarilla.

7. El calzado debe ser exclusivo de la zona de actividad quirúrgica.

8. Se continúa recomendando el lavado quirúrgico con solución de gluconato de clorhexidina con alcohol.

9. Se debe utilizar equipo de protección individual y sobre este, el equipo estéril necesario para la intervención quirúrgica.

Para el retiro del equipo de protección también deben de tenerse en consideración algunas recomendaciones. De preferencia debería realizarse en una sala de quirófano sucia o realizarse de manera individual.

Se debe realizar de la manera más cautelosa posible evitando la salpicadura o la contaminación del equipo de quirófano o el equipo de anestesia.

1. Retirase la bata y los guantes quirúrgicos como normalmente se hacen, evitando el contacto o salpicaduras.

2. Se debe desinfectar los guantes del equipo de protección individual.

3. Retirar la pantalla protectora sin contaminar.

4. Lavado con desinfectante.

5. Se retiran los guantes de protección individual y se descartan en un contenedor cuidando de no tocarlos o lanzar los mismos. acuosa.

6. Desinfección de manos con alcohol base

7. Retiro de la bata protectora.
8. Desinfección de manos de nuevo.

9. Retiro de Gafas con los ojos y boca cerradas.

10. Desinfección de manos

11. Retiro de la mascarilla con los ojos y la boca cerrados tomándolo de las cintas y no hacer contacto con la parte anterior de la misma ya que puede estar contaminada

12. Desinfección de manos.

13. Salir del quirófano

14. Desinfección de calzado.

15. Lavado de quirúrgico de manos con gluconato de clorhexidina de base alcohol.

16. Revisión y registro por posible contaminación inadvertida.

17. Se recomienda la ducha rutinaria.

Uno de los puntos indispensables a tratar es el manejo que debe darle el cirujano a pacientes con sospecha de infección por COVID 19. Si se ha tenido contacto estrecho con un caso probable de infección de alto riesgo sin equipo de protección adecuado se deberá de retirar al profesional de su actividad asistencial durante 14 días; si el paciente es de bajo riesgo el profesional continuara con actividad asistencial normal. Si se tuvo un contacto casual con un caso probable de infección sin equipo adecuado de protección el profesional deberá continuar con la actividad asistencial normal y se dará vigilancia pasiva.

Es importante tomar en cuenta que cualquier paciente que consulte a la emergencia del centro asistencial es un posible caso sospechoso, por lo que es necesario realizar una historia clínica y una exploración física completos tomando en cuenta factores determinantes que puedan hacer sospechar que el paciente cursa con un cuadro respiratorio. Se debe tomar muy en cuenta los antecedentes de viajes al extranjero, así como contacto con personas que hayan realizado viajes a países de alto riesgo o países en los cuales ya se cuente con casos confirmados de COVID 19. Sin embargo, no es necesario realizar pruebas diagnósticas para la infección de COVID 19 a todos los pacientes que vayan a recibir algún tipo de tratamiento quirúrgico.

En el Hospital Regional de Occidente se realizaron 128 cirugías de emergencia y 39 electivas haciendo un total de 167 procedimientos en un lapso de 23 días desde que se diagnosticará el primer caso de COVID-19 en Guatemala, por lo que las medidas de bioseguridad deben ser especialmente estrictas en estos momentos en donde el virus se encuentra propagándose y las probabilidades 
de estar en contacto con pacientes sospechosos o incluso positivos a COVID-19 son altas. Es interesante que en España consideran contraindicado cualquier procedimiento quirúrgico en pacientes positivos a COVID-19. Sin embargo, esto difícilmente sea aplicable a nuestro centro, dada la alta prevalencia de pacientes politraumatizados, heridas de arma blanca y arma de fuego, y otros procedimientos que no pueden diferirse.

Será un reto en un futuro no muy lejano implementar las medidas de seguridad en estos procedimientos si en un dado caso se presentara un paciente positivo a COVID-19 o por la urgencia del mismo no se llegará a tener una historia completa del paciente.

Es sumamente relevante que el personal médico y paramédico que se encuentran en los diferentes centros asistenciales refuercen de manera inmediata su sistema de bioseguridad y si no existe, crear uno lo antes posible, para evitar el contagio de esta enfermedad y proteger la vida no solo del paciente si no de los trabajadores de salud tanto de entidades públicas y privadas. El futuro es incierto, y nos planteamos varias interrogantes. ¿Qué comportamiento tendrá en nuestro país este virus? No sabemos; ¿llegaremos a nuestro limite en el cual tendremos que decidir si el paciente muere por falla respiratoria por COVID-19 o por un choque séptico por perforación intestinal o un cuadro de apendicitis aguda complicada? Es lamentable la situación en la que se encuentra no solo nuestro país si no el mundo entero, por lo que debemos protegernos unos a otros para minimizar el riesgo tanto para el personal de salud como para el paciente.

\section{REFERÊNCIAS}

Organización Mundial de la Salud, https:// www.who.int/es/emergencies/diseases/novelcoronavirus-2019/advice-for-public/q-a-coronaviruses.

Yu GY, Lou Z, Zhang W. [Several suggestion of operation for colorectal cancer under the outbreak of Corona Virus Disease 19 in China]. Zhonghua Wei Chang Wai Ke Za Zhi. 2020 Feb 19;23(3):9-11

Gobierno de España. Ministerio de Sanidad. Dirección General de salud pública, calidad e innovación. Centro de Coordinación de Alertas y Emergencias Sanitarias. Procedimiento de Actuación frente a casos de Infección por el nuevo coronavirus (SARS-
CoV-2), actualizado a 11 de marzo de 2020.

Surgical Care and Coronavirus Disease 2019 (COVID-19). American College of Surgeons https://www.facs. org/about-acs/covid-19/information-for-surgeons 